\title{
Polysome profiling reveals broad translatome remodeling during endoplasmic reticulum (ER) stress in the pathogenic fungus Aspergillus fumigatus
}

Karthik Krishnan ${ }^{1}$, Zhaowei Ren ${ }^{2}$, Liliana Losada ${ }^{3}$, William C Nierman ${ }^{3}$, Long Jason Lu² and David S Askew ${ }^{1,4^{*}}$

\begin{abstract}
Background: The unfolded protein response (UPR) is a network of intracellular signaling pathways that supports the ability of the secretory pathway to maintain a balance between the load of proteins entering the endoplasmic reticulum (ER) and the protein folding capacity of the ER lumen. Current evidence indicates that several pathogenic fungi rely heavily on this pathway for virulence, but there is limited understanding of the mechanisms involved. The best known functional output of the UPR is transcriptional upregulation of mRNAs involved in ER homeostasis. However, this does not take into account mechanisms of translational regulation that involve differential loading of ribosomes onto mRNAs. In this study, a global analysis of transcript-specific translational regulation was performed in the pathogenic mold Aspergillus fumigatus to determine the nature and scope of the translational response to ER stress.
\end{abstract}

Results: ER stress was induced by treating the fungus with dithiothreitol, tunicamycin, or a thermal up-shift. The mRNAs were then fractionated on the basis of ribosome occupancy into an under-translated pool $(U)$ and a well-translated pool (W). The mRNAs were used to interrogate microarrays and the ratio of the hybridization signal $(W / U)$ was used as an indicator of the relative translational efficiency of a mRNA under each condition. The largest category of translationally upregulated mRNAs during ER stress encoded proteins involved in translation.

Components of the ergosterol and GPI anchor biosynthetic pathways also showed increased polysome association, suggesting an important role for translational regulation in membrane and cell wall homeostasis. ER stress induced limited remodeling of the secretory pathway translatome. However, a select group of transcription factors was translationally upregulated, providing a link to subsequent modification of the transcriptome. Finally, we provide evidence that one component of the ER stress translatome is a novel mRNA isoform from the yvcl gene that is induced by ER stress in a UPR-dependent manner.

Conclusions: Together, these findings define a core set of mRNAs subject to translational control during the adaptive response to acute ER stress in A. fumigatus and reveal a remarkable breadth of functions that are needed to resolve ER stress in this organism.

Keywords: Aspergillus fumigatus, UPR, Unfolded protein response, ER stress, Translational regulation, Polysome profiling, Yvc1

\footnotetext{
* Correspondence: david.askew@uc.edu

'Department of Pathology \& Laboratory Medicine, University of Cincinnati

College of Medicine, 231 Albert Sabin Way, Cincinnati, OH 45267-0529, USA

${ }^{4}$ Department of Pathology, University of Cincinnati, PO Box 670529,

Cincinnati, OH 45267-0529, USA

Full list of author information is available at the end of the article
} 


\section{Background}

The opportunistic mold pathogen Aspergillus fumigatus causes life-threatening pulmonary infections that have the potential to progress into invasive aspergillosis, a disseminated disease with a very high rate of mortality $[1,2]$. Infections with this fungus continue to impede the successful management of patients with hematologic malignancies or solid-organ and bone marrow transplants worldwide, accounting for the highest per person hospitalization costs of all the systemic mycoses [3-5]. The ongoing expansion of the immunosuppressed population is expected to increase the incidence of the disease, which is galvanizing studies to understand more about fungal stress response pathways that could yield novel vulnerabilities for future therapeutic targeting.

Current evidence indicates that pathogenic fungi are under endoplasmic reticulum (ER) stress in the host environment and therefore depend upon adaptive stress responses pathways to support their survival during infection [6-10]. The unfolded protein response (UPR) is the major ER stress response pathway, responsible for maintaining an ER lumenal environment that is conducive to optimal protein folding [11]. A. fumigatus depends upon the UPR to support the expression of clinically relevant traits such as thermotolerance, cell wall/membrane homeostasis, hypoxia adaptation, iron homeostasis, nutrient assimilation from complex substrates and antifungal drug resistance [6,7]. Similar findings have also been reported in Cryptococcus neoformans [8], Candida albicans [12], Candida glabrata [10], and Alternaria brassicicola [9], suggesting that the UPR is used by diverse fungal pathogens as a regulatory hub for the expression of multiple attributes that promote virulence in the host. The UPR is triggered in response to the accumulation of unfolded proteins, a condition that arises during infection when there is an imbalance between the level of nascent proteins entering the ER and the ability of the organelle to process that load. ER protein folding may also be perturbed by adverse conditions encountered in the host such as mammalian body temperature, oxidative stress, hypoxia and nutrient limitation [13]. The UPR counters the resulting ER stress by expanding the quantity of ER-resident chaperones and folding enzymes that are needed to help membrane and secreted proteins achieve their native conformation. The current understanding of the fungal UPR is based upon the paradigm established in the model yeast Saccharomyces cerevisiae [14]. The pathway is controlled by Ire1 (IreA in A. fumigatus), an ERtransmembrane protein that detects disturbances in the ER that lead to the accumulation of unfolded proteins. Ire1 contains a lumenal sensing domain and a cytosolic effector region that contains dual enzymes: a kinase linked to an endoribonuclease (RNase). In the absence of ER stress, Ire1p exists as an inactive monomer in association with the ER-resident chaperone, Bip (also known as Kar2p). When the folding capacity of the ER is exceeded, BiP dissociates from the lumenal domain to assist with protein folding. This triggers the activation of Ire1 by a ligand-dependent two-step mechanism in which BiP dissociation is followed by direct interaction of Ire1 with unfolded proteins [15-18]. These events elicit Ire1 oligomerization in the ER membrane, resulting in a conformational change that activates the C-terminal RNase $[19,20]$. The substrate of this RNAse is a cytoplasmic mRNA known as HAC1 (hacA in A. fumigatus). The excision of an unconventional intron from the HAC1 mRNA allows in-frame translation of the bZIP transcription factor, Hac1 (HacA in A. fumigatus). Hac1 re-establishes ER homeostasis by remodeling the transcriptome to enhance the protein folding capacity of the ER.

Genome-wide expression profiling has demonstrated that A. fumigatus responds to acute ER stress by upregulating the levels of a core group of mRNAs that encode proteins with functions that support the secretory pathway [6]. However, mRNA abundance measurements do not take translational efficiency into consideration, which is a mechanism of gene regulation that can have potent effects on protein production [21-23]. Translational regulation provides the cell with a rapid-response mechanism to fine-tune protein levels in proportion to need, and is particularly important in situations where an immediate response to an environmental stress is key for survival [24,25]. Translational regulation can be studied on a global scale by interrogating microarrays with mRNAs that have been fractionated based upon ribosome occupancy [26]. This approach is based on the fact that translationally quiescent mRNAs are sequestered within messenger ribonucleoprotein (mRNP) particles or associated with single ribosomes (monosomes), whereas actively translated mRNAs are associated with multiple ribosomes (polysomes). The hybridization of a microarray with these polysome-fractionated mRNAs can thus provide insight into how the translational efficiency of individual mRNAs is modified by environmental cues. Analogous approaches have been used to study the ER stress translatome in $S$. cerevisiae and Aspergillus niger $[27,28]$. However, a global analysis of transcriptspecific translational regulation has not been performed in $A$. fumigatus. In this study, polysome fractionation of mRNA was coupled with microarray detection in order to identify changes in the translational status of the A. fumigatus transcriptome under conditions that perturb ER homeostasis. The findings establish a core ER stress translatome and uncover evidence for extensive translational regulation during the response of $A$. fumigatus to ER stress. 


\section{Results \& discussion}

Translatome remodeling is a major component of the ER stress response in $A$. fumigatus

The two most commonly used compounds to induce ER stress are dithiothreitol (DTT), which reduces disulfide bonds, and tunicamycin (TM), which inhibits the $\mathrm{N}$-linked glycosylation that is required for optimal folding [29]. We have previously shown that treatment of $A$. fumigatus with $1 \mathrm{mM}$ DTT or $10 \mu \mathrm{g} / \mathrm{ml}$ TM for $1 \mathrm{~h}$ is sufficient to trigger the UPR, defined by the induction of hacA splicing and a subsequent remodeling of the transcriptome to strengthen the protein folding capacity of the ER $[6,7]$. In the present study, we found that these conditions had undetectable effects on the overall polysome distribution in A. fumigatus (data not shown); both control and treated cultures showed a typical polysome profile comprised of individual ribosome subunits, the $80 \mathrm{~S}$ monosome peak, and polysome peaks representing 2-10 ribosomes per mRNA (Figure 1). This is similar to S. cerevisiae, where treatment with DTT did not result in substantial reductions in global translation initiation efficiency [27]. However, it contrasts the situation in metazoans, where the analogous treatments induce global translation attenuation due to phosphorylation of eukaryotic translation initiation factor $2 \alpha$ (eIF $2 \alpha)$, thereby reducing the total burden on the secretory pathway [30]. The apparent absence of a global translation attenuation response to ER stress in fungi is consistent with current evidence that the fungal kingdom lacks the ER stress sensor that controls the activation of this pathway [11,31].

We hypothesized that a subset of mRNAs that are important to surviving ER stress would redistribute into the polysome peak to enhance their rate of translation. To test this, a genome-wide perspective of mRNA translational efficiency during ER stress was obtained by interrogating microarrays with mRNAs that were fractionated on the basis of ribosome occupancy. ER stress was induced by treating the fungus with DTT or TM, as detailed in Methods. Ribosome-associated mRNAs were then fractionated from cytoplasmic extracts into two pools: an under-translated pool (fraction- $U$ ) containing mRNAs with four or less ribosomes and a well-translated pool (fraction-W) containing mRNAs with five or more ribosomes (Figure 1). Each fraction was then used to interrogate high-density microarrays and an estimate of the translational efficiency of each mRNA was defined here as the ratio of the hybridization signal in fraction-W over that of fraction-U. Those mRNAs that showed a two-fold change (up or down) in this translational efficiency ratio during ER stress were considered to be subject to translational regulation during ER stress (see Methods for additional detail). To maximize the detection of ER stressresponsive mRNAs, and minimize chemical-specific effects, the resulting dataset was restricted to mRNAs that

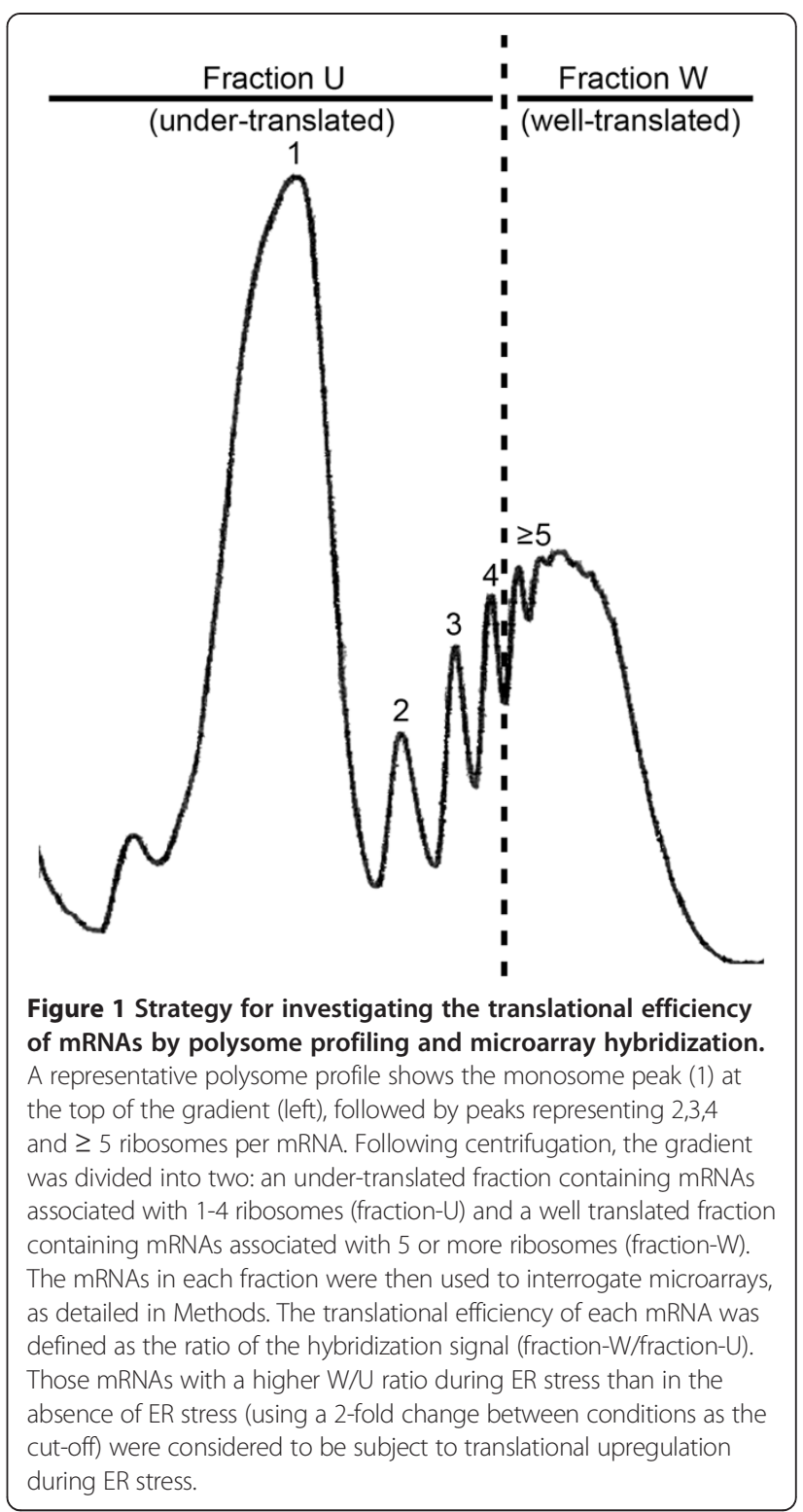

showed differential polysome association in response to both DTT and TM treatment. Of the 323 mRNAs that fit these criteria (Figure 2) the majority showed an increase in translational efficiency (233), suggesting that ER stressinduced translational regulation is predominantly an inductive response. It is noteworthy that the number of translationally regulated mRNAs in this analysis was over four times the size of the transcriptional response previously identified under the same conditions [6], demonstrating that remodeling of the translatome is a major component of the ER stress response in A. fumigatus. Validation of the microarray data was obtained by qPCR for 3 upregulated mRNAs (erg1, vps55, and jlbA) and one negative control ( $\beta$-tubulin) (Additional file 1$)$.

A total of 90 mRNAs showed a decrease in translational efficiency in response to DTT and TM treatment 


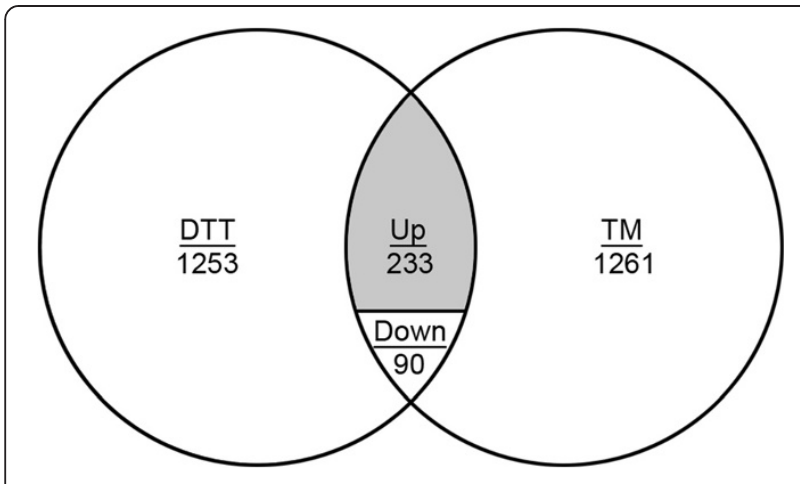

Figure 2 Translationally regulated transcripts during ER stress in $A$. fumigatus. The Venn diagram demonstrates the number of transcripts with a differential translational efficiency ratio in the presence of DTT or TM relative to untreated cultures (minimum 2-fold change in the W/U ratio). The region of overlap illustrates the number of mRNAs that are shared between the two treatments, representing mRNAs that are enriched for functions in ER stress response. The overlap contains translationally upregulated mRNAs (shaded region) as well as downregulated (Down). The area of each circle is scaled to the number of transcripts and the values for DTT and TM represent the total number of genes that were differentially regulated.
(Figure 2), 46 of which were unannotated. Analysis of the remaining 44 mRNAs using the Kyoto Encyclopedia of Genes and Genomes (KEGG) database revealed enrichment in metabolism and RNA processing categories, consistent with a shift towards more limited metabolic functions under ER stress conditions (Additional file 2). Of the 1253 mRNAs that showed altered translational efficiency in response to DTT alone, 536 were downregulated. This contrasts a study of translational efficiency during DTT-induced stress in $A$. niger, which revealed down-regulation of 253 mRNAs and upregulation of 26 mRNAs. A direct comparison between these two datasets is difficult however, because the $A$. niger paper treated the fungus with $20 \mathrm{mM}$ DTT for $2 \mathrm{~h}$ and fractionated mRNAs based upon occupancy with $<2$ and $\geq 2$ ribosomes [28], whereas our study used $1 \mathrm{mM}$ DTT for $1 \mathrm{~h}$ and fractionation into pools associated with $<5$ and $\geq 5$ ribosomes. The more severe ER stress conditions used in the $A$. niger study may account for the predominance of translationally repressed mRNAs in that organism, relative to the largely inductive response in A. fumigatus.

\section{ER stress induces limited remodeling of the secretory pathway translatome}

The transcriptional response of $A$. fumigatus to acute ER stress is narrowly focused on upregulating the level of mRNAs that encode proteins that support the secretory pathway at multiple levels, including functions such as folding, glycosylation, ER-associated degradation, ER translocation, vesicular transport and membrane function
[6]. The majority of these proteins (70\%) contained predicted signal peptides that would direct them into the ER. However, only $18 \%$ of the translationally upregulated mRNAs identified in the present study contained signal peptides. Furthermore, a KEGG pathway- enrichment analysis revealed that only a minority $(16 \%)$ of the mRNAs in the translationally upregulated dataset encode proteins that directly influence the secretory pathway (Table 1). In fact, none of the translationally upregulated mRNAs in this study showed increased abundance in our previous analysis of the UPR transcriptome under the identical conditions [6]. This demonstrates that the nature and scope of ER stress-induced translational regulation is fundamentally different from the transcriptional response to the same stress. Nevertheless, the identification of several transcription factor-encoding mRNAs in the translationally upregulated dataset (Table 1 ) suggests a mechanism whereby rapid changes in the translatome could be linked to subsequent modification of the transcriptome during ER stress. Together, these mechanisms would provide the fungus with extensive options to modify the proteome and restore ER homeostasis.

\section{ER stress increases the translational state of the translation machinery}

We found that components of the translational machinery were subject to increased polysome association in the presence of either DTT or TM (Table 1). This was somewhat surprising, since previous studies have shown downregulation of ribosome biogenesis genes in $A$. niger and $S$. cerevisiae exposed to DTT $[27,28]$. This discrepancy is likely to reflect the higher concentrations of DTT used in those studies, and/or species-specific differences in sensitivity to DTT. We speculate that a limited expansion of the translational apparatus is beneficial to A. fumigatus during ER stress because it provides a mechanism to rapidly increase the level of proteins that are needed to protect the ER from damage until the appropriate transcriptional modifications can be implemented. Since only a subset of the translational machinery was upregulated in A. fumigatus, a second possibility is that some of these proteins may have unrecognized 'moonlighting' functions that are relevant to ER stress responses, a possibility that is supported by an emerging literature on extra-ribosome functions for ribosomal proteins [32].

\section{ER stress induces remodeling of the cell wall and membrane translatome}

The major interface between $A$. fumigatus and the host environment is the plasma membrane and cell wall, both of which are important targets for current antifungal therapy [33]. Damage to either of these structures requires the delivery of new cell wall and membrane components to the hyphal tips, which increases the stress on 
Table 1 List of mRNAs with increased polysome association during ER stress (treatment with DTT or TM)

\begin{tabular}{|c|c|c|}
\hline DTT & TM & mRNA \\
\hline \multicolumn{3}{|c|}{ Ribosomal proteins/translation } \\
\hline 2.81 & 2.92 & 605 ribosomal protein L27a (AFUA_3G05600) \\
\hline 2.15 & 3.20 & 40 S ribosomal protein S29 (AFUA_6G12720) \\
\hline 2.87 & 2.26 & 40 S ribosomal protein S8 (AFUA_6G07360) ${ }^{\#}$ \\
\hline 2.80 & 2.16 & 50 S ribosomal protein L36 (AFUA_4G12810) \\
\hline 2.59 & 2.32 & 375 ribosomal protein S16 (AFUA_5G08350) \\
\hline 1.48 & 2.60 & Mitochondrial ribosomal protein L11 (AFUA_5G11830) \\
\hline 2.01 & 1.93 & Ribosome biogenesis protein (AFUA_8G04790) \\
\hline 1.18 & 2.49 & 375 ribosomal protein S5 (AFUA_5G11540) \\
\hline 1.51 & 1.93 & 40S ribosomal protein S9 (AFUA_3G06970) \\
\hline 1.01 & 2.42 & 40 ribosomal protein Rps16 (AFUA_2G10500) ${ }^{\#}$ \\
\hline 1.07 & 2.20 & 605 ribosomal protein L6 (AFUA_6G09060) \\
\hline 4.51 & 2.08 & Aconitate hydratase/Mitochondrial ribosomal protein subunit L49 (AFUA_3G08080) \\
\hline 3.11 & 1.36 & Eukaryotic translation initiation factor 3 subunit elF-Ca (AFUA_1G05200) \\
\hline 1.72 & 2.49 & Translation elongation factor eEF-1B gamma subunit, putative (AFUA_1G17120) \\
\hline 1.27 & 2.52 & GTP binding protein Guf1 (AFUA_3G14350) \\
\hline 1.86 & 1.05 & Eukaryotic translation initiation factor 3 subunit elF-Ck (AFUA_3G09280) \\
\hline \multicolumn{3}{|c|}{ Cell membrane/cell wall } \\
\hline 1.08 & 6.34 & Squalene monooxygenase Erg1 (AFUA_5G07780) \\
\hline 1.61 & 1.43 & Ergosterol biosynthesis protein Erg28 (AFUA_2G11550) \\
\hline 1.37 & 1.39 & 1,3-beta-glucanosyltransferase Gel2 (AFUA_6G11390) \\
\hline 3.51 & 4.88 & Cell wall proline rich protein (AFUA_1G13450) \\
\hline 2.59 & 3.62 & Actin cortical patch protein Sur7 (AFUA_2G02310) \\
\hline 4.21 & 2.23 & CFEM domain protein (AFUA_6G14090) \\
\hline 1.36 & 1.89 & GPI anchored protein (AFUA_2G07800) \\
\hline 1.78 & 1.01 & GPI anchored dioxygenase (AFUA_3G01800) \\
\hline 1.24 & 3.13 & Dolichol phosphate-mannose biosynthesis regulatory protein Dpm2 (AFUA_1G03020) \\
\hline 1.32 & 1.05 & N-acetylglucosaminyl-phosphatidylinositol deacetylase, putative (AFUA_5G12550) \\
\hline 1.10 & 2.58 & Integral membrane protein (Pth11) (AFUA_6G03600) \\
\hline \multicolumn{3}{|c|}{ Protein folding \& modification } \\
\hline 1.29 & 2.48 & Alpha-1,2-mannosyltransferase (Alg2) (AFUA_5G13210) \\
\hline 1.83 & 2.58 & Disulfide isomerase (TigA) (AFUA_5G12260) \\
\hline 1.04 & 2.84 & Protein disulfide isomerase Pdi1 (AFUA_2G06150) \\
\hline 1.04 & 1.82 & N-acetyltransferase family protein (AFUA_4G10930) \\
\hline 1.35 & 1.47 & N-acetyltransferase complex ARD1 subunit (AFUA_1G09600) \\
\hline 2.11 & 2.89 & Prefoldin subunit 5 (AFUA_1G10740) ${ }^{\#}$ \\
\hline \multicolumn{3}{|c|}{ Endosome/protein transport and sorting } \\
\hline 1.71 & 1.94 & Rho GTPase activator (Bem3) (AFUA_6G06400) \\
\hline 1.69 & 1.41 & Fasciclin domain family protein (AFUA_1G14300) \\
\hline 3.75 & 1.50 & Ras-like GTP-binding protein (AFUA_4G03100) \\
\hline 1.39 & 2.26 & Endosomal cargo receptor (Erv14) (AFUA_6G07290) \\
\hline 1.58 & 2.16 & Synaptobrevin-like protein Sybl1 (AFUA_6G11270) \\
\hline 1.57 & 3.04 & RAB GTPase Vps21/Ypt51 (AFUA_3G10740)" \\
\hline 5.38 & 2.13 & Vacuolar protein sorting 55 superfamily (AFUA 6G04780) \\
\hline
\end{tabular}


Table 1 List of mRNAs with increased polysome association during ER stress (treatment with DTT or TM) (Continued)

\begin{tabular}{|c|c|c|}
\hline 1.03 & 2.77 & AP-1 adaptor complex subunit sigma (AFUA_2G01570) \\
\hline 1.93 & 1.75 & Mitochondrial import inner membrane translocase subunit (TIM22) (AFUA_5G02200) \\
\hline \multicolumn{3}{|c|}{ Transcription } \\
\hline 3.07 & 3.04 & bZIP transcription factor JlbA/IDI-4 (AFUA_5G01650)" \\
\hline 1.88 & 3.90 & CBF/NF-Y family transcription factor (AFUA_2G14250) \\
\hline 4.34 & 1.41 & C6 transcription factor (AFUA_3G09130) \\
\hline 2.03 & 3.35 & Transcription factor RfeF (AFUA_4G10200) \\
\hline 1.03 & 4.24 & CP2 transcription factor (AFUA_1G17350) \\
\hline 3.09 & 1.71 & bZIP transcription factor (LziP) (AFUA_1G16460) \\
\hline 1.84 & 2.39 & Transcription initiation factor TFIID, 31 kd subunit, putative (AFUA_1G14600) \\
\hline 2.18 & 1.29 & C6 transcription factor (AFUA_6G11230) \\
\hline 1.48 & 1.08 & RNA polymerase II mediator complex component Srb8, putative (AFUA_3G06250) \\
\hline 1.63 & 3.90 & $\mathrm{CHCH}_{\text {domain }}$ protein (AFUA_3G06370) ${ }^{\#}$ \\
\hline 2.44 & 1.48 & Nitrogen metabolite repression regulator NmrA (AFUA_5G02920) \\
\hline \multicolumn{3}{|c|}{ Stress response } \\
\hline 1.24 & 1.99 & General stress response phosphoprotein phosphatase Psr1/2 (AFUA_1G04790) ${ }^{\#}$ \\
\hline 4.37 & 3.43 & Glutathione peroxidase Hyr1 (AFUA_3G12270) \\
\hline
\end{tabular}

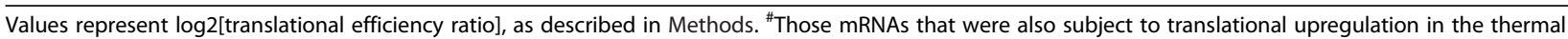
stress dataset $\left(37^{\circ} \mathrm{C}, 60 \mathrm{~min}\right)$.

the secretory pathway [7]. In this study, we found that the translational efficiency ratios for erg1 and erg28 mRNAs, encoding two key steps in the ergosterol pathway, increased in the presence of DTT or TM (Table 1). We have previously shown that these mRNAs do not increase in unfractionated total RNA under these same conditions [6], suggesting that they are under translational control. Northern blot analysis of polysomefractionated RNA confirmed these findings; the amount of $\operatorname{erg} 1$ mRNA that was loaded by 5 or more ribosomes was greater in the presence of DTT, indicating enhanced translation efficiency (Figure 3). It interesting to note that in addition to its enzymatic function, Erg28 has a unique role as an ER transmembrane protein that acts as a scaffold to tether other members of the ergosterol biosynthetic complex into a single functioning unit [34]. Thus, an increase in the translational efficiency of erg28, and potentially other ergosterol biosynthetic mRNAs, could work in concert with UPR-mediated transcriptional increases to drive flux through the sterol pathway and support membrane homeostasis. To our knowledge, this is the first evidence that mRNAs encoding ergosterol biosynthetic enzymes are subject to translational control in A. fumigatus. Since overexpression of mRNAs involved in sterol biosynthesis is an established mechanism of triazole antifungal drug resistance [35], it is intriguing to speculate that an increase in the translational efficiency of a mRNA in this pathway, even without a change in mRNA abundance, could represent a previously overlooked mechanism of antifungal drug resistance.

A. fumigatus $\beta(1-3)$ glucanoxyltransferases (Gel1 and Gel2) catalyze the elongation of $\beta(1-3)$ glucan side chains and influence morphogenesis and virulence [36,37]. A previous report indicates that both Gel1 and Gel2 are constitutively transcribed in A. fumigatus [37]. However, here we demonstrate that the translational efficiency of the gel2 mRNA increases 2.5 fold during ER stress, suggesting that an increase in Gel2 protein is needed to protect the wall under these conditions. Gel2 contains a glycosylphosphatidylinositol (GPI) anchor that tethers it to the plasma membrane [37], which facilitates its role in maintaining cell wall integrity. Interestingly, at least three other mRNAs encoding GPI-anchored proteins of unknown function also showed increased ribosome occupancy during ER stress. In addition, ER stress caused increased polysome association of the mRNA encoding the major regulatory component for the rate-limiting step in GPI anchor biosynthesis, Dpm2, as well as the subsequent enzyme in the pathway, AfPIG-L. Together, these findings argue that rapid translation of GPI-anchored proteins is necessary to protect the fungus under conditions that disrupt ER homeostasis, mostly likely due to their role in maintaining the cell wall [37-39]. It is worth noting that GPI anchor biosynthesis is an emerging target for the development of new antifungal therapy [40-42]. Further understanding of the mechanism(s) by which translational regulation impacts GPI anchor production could suggest 


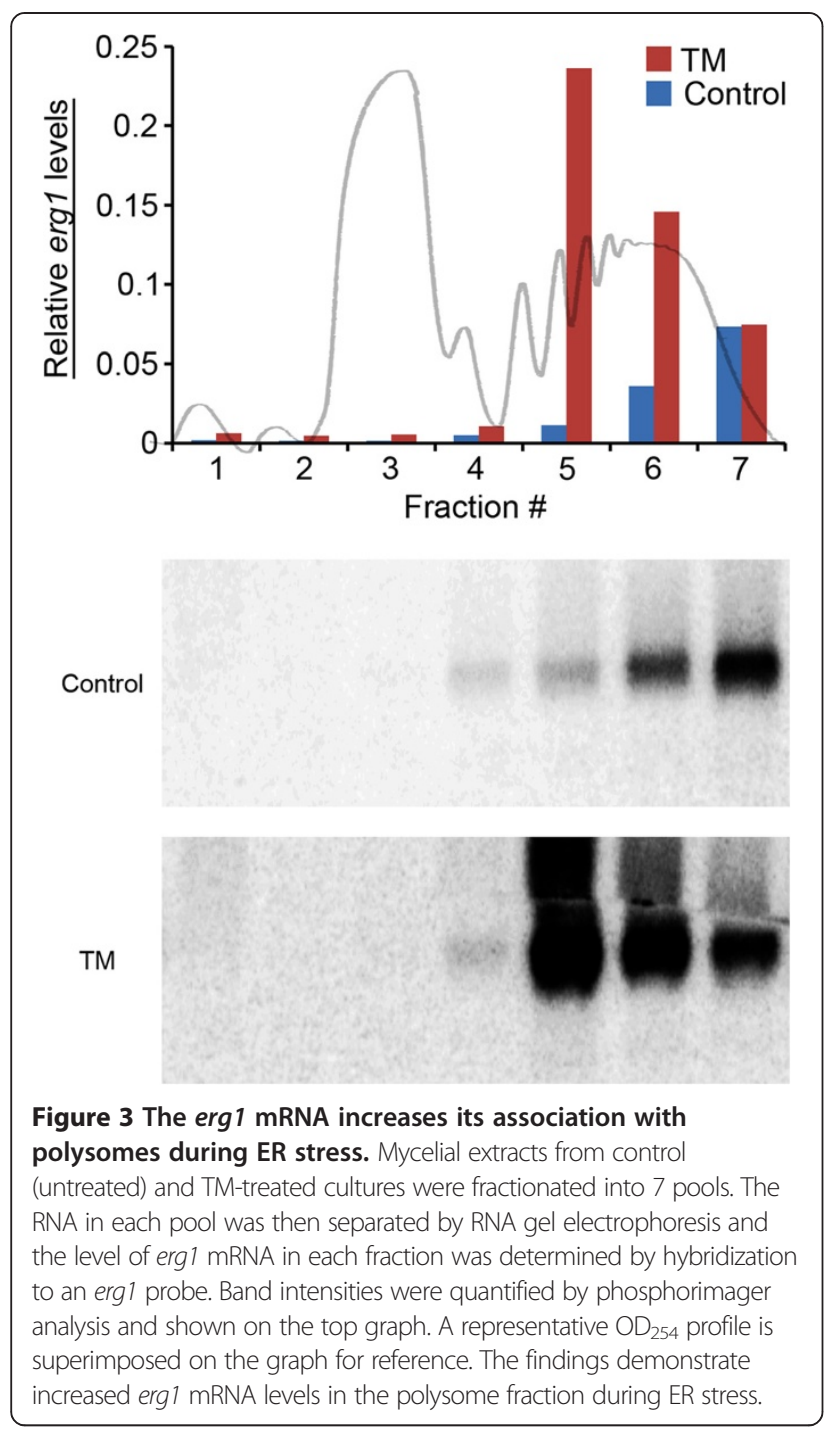

novel strategies to enhance pharmacologic inhibition of this pathway.

\section{Host-temperature adaptation involves distinct translatome remodeling}

The primary ecological niche for A. fumigatus in nature is composting organic material, an environment that undergoes constant fluctuations in temperature as a consequence of complex microbial activity. A. fumigatus has evolved mechanisms to thrive under these conditions, and is considered one of the most thermotolerant species of mold [43]. Since elevated temperatures induce conformational changes in proteins [44], an increase in temperature is likely to engage pathways that are relevant to ER stress response. We therefore compared the translational efficiency of A. fumigatus mRNAs at $25^{\circ} \mathrm{C}$, representing the environment, to that of mRNAs following a shift to $37^{\circ} \mathrm{C}$, reflecting adaptation to the mammalian host. Ribosome fractionation showed that total polysome levels increased within $30 \mathrm{~min}$ of the shift to $37^{\circ} \mathrm{C}$, consistent with the need for increased proteins at this optimal growth temperature (Figure 4). Polysome peak heights declined somewhat after $60 \mathrm{~min}$ at $37^{\circ} \mathrm{C}$, presumably reflecting a return to steady-state levels at the new temperature. Two criteria were employed to define differentially translated mRNAs during this transition. First, we considered all mRNAs that shifted from fraction- $U$ to fraction-W following the temperature shift to have a temperature-induced increase in translational efficiency (two-fold cutoff). This resulted in the identification of 311 translationally upregulated mRNAs $30 \mathrm{~min}$ after the temperature shift, and a total of 499 mRNAs at the $1 \mathrm{~h}$ time-point. Some of these mRNAs could also be upregulated at the level of transcript abundance during ER stress. Thus, in order to enrich for mRNAs that are predominantly regulated at the level of translational efficiency, the dataset was narrowed to those mRNAs that showed a minimal two-fold increase in translational efficiency ratio when normalized to relative transcript abundance in unfractionated RNA. Applying these criteria, $78 \%$ of mRNAs were translationally upregulated at the 30 min time-point and $75 \%$ were upregulated at the $1 \mathrm{~h}$ time-point. These findings demonstrate that thermal stress is similar to DTT- and TM-induced ER stress in its reliance on translational regulation as a rapidresponse mechanism to manufacture essential proteins that are needed to protect the fungus during hosttemperature adaptation.

Hierarchical clustering of all mRNAs that showed temperature-dependent increases in translational efficiency fell into three major clusters (Figure 5). The first group ('early') showed a transient increase in translational efficiency at $30 \mathrm{~min}$ that returned to baseline levels by $1 \mathrm{~h}$. The second group ('late') showed baseline levels at $30 \mathrm{~min}$ but an increase at $1 \mathrm{~h}$. The third group ('continuous') showed an increase at $30 \mathrm{~min}$ that was sustained at $1 \mathrm{~h}$ or subject to a further increase. Over-represented functional groups in the entire dataset of translationally upregulated mRNAs at $37^{\circ} \mathrm{C}$ included nucleotide metabolism (28), ribosome function (18), oxidative phosphorylation (26), TCA cycle (8), cell cycle (23), and secondary metabolism (18) (Additional file 3). The increased translation of mRNAs encoding proteins with roles in metabolism following the temperature shift is consistent with the fact that A. fumigatus grows more rapidly at $37^{\circ} \mathrm{C}$ than it does at $25^{\circ} \mathrm{C}$. However, some metabolic genes were also enriched in the downregulated category (see the full dataset, ArrayExpress accession E-MTAB-2027), indicating that complex metabolic adjustments are operational during the transition from $25^{\circ} \mathrm{C}$ to $37^{\circ} \mathrm{C}$. Interestingly, we found that mRNAs encoding heat-shock proteins were largely absent from the dataset of translationally upregulated mRNAs following the shift from $30^{\circ} \mathrm{C}$ to $37^{\circ} \mathrm{C}$. However, this is 


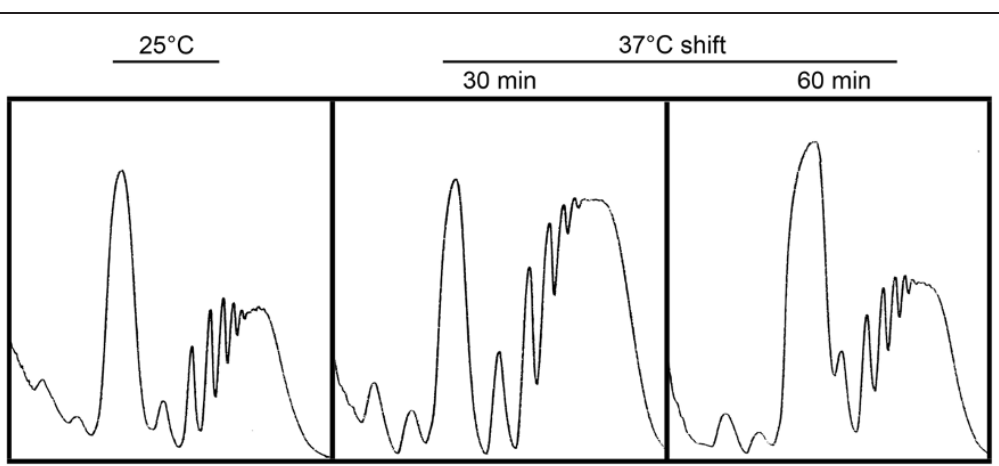

Figure 4 Effects of a temperature shift on the polysome profile $\boldsymbol{A}$. fumigatus. Overnight cultures at $25^{\circ} \mathrm{C}$ were shifted to $37^{\circ} \mathrm{C}$ and polysome profiles were prepared from mycelial extracts at the indicated times.

congruent with previous transcriptomic analyses, which showed little upregulation of heat-shock protein-encoding mRNAs under these conditions $[45,46]$. We speculate that the transition from $30^{\circ} \mathrm{C}$ to $37^{\circ} \mathrm{C}$ is a relatively mild stress for this thermotolerant fungus, requiring minimal upregulation of heat-shock proteins for protection, either at the transcriptional or translational levels.

The Venn diagram in Figure 6 illustrates the overlap between the transcripts that were translationally upregulated in response to the 3 types of ER stress applied in

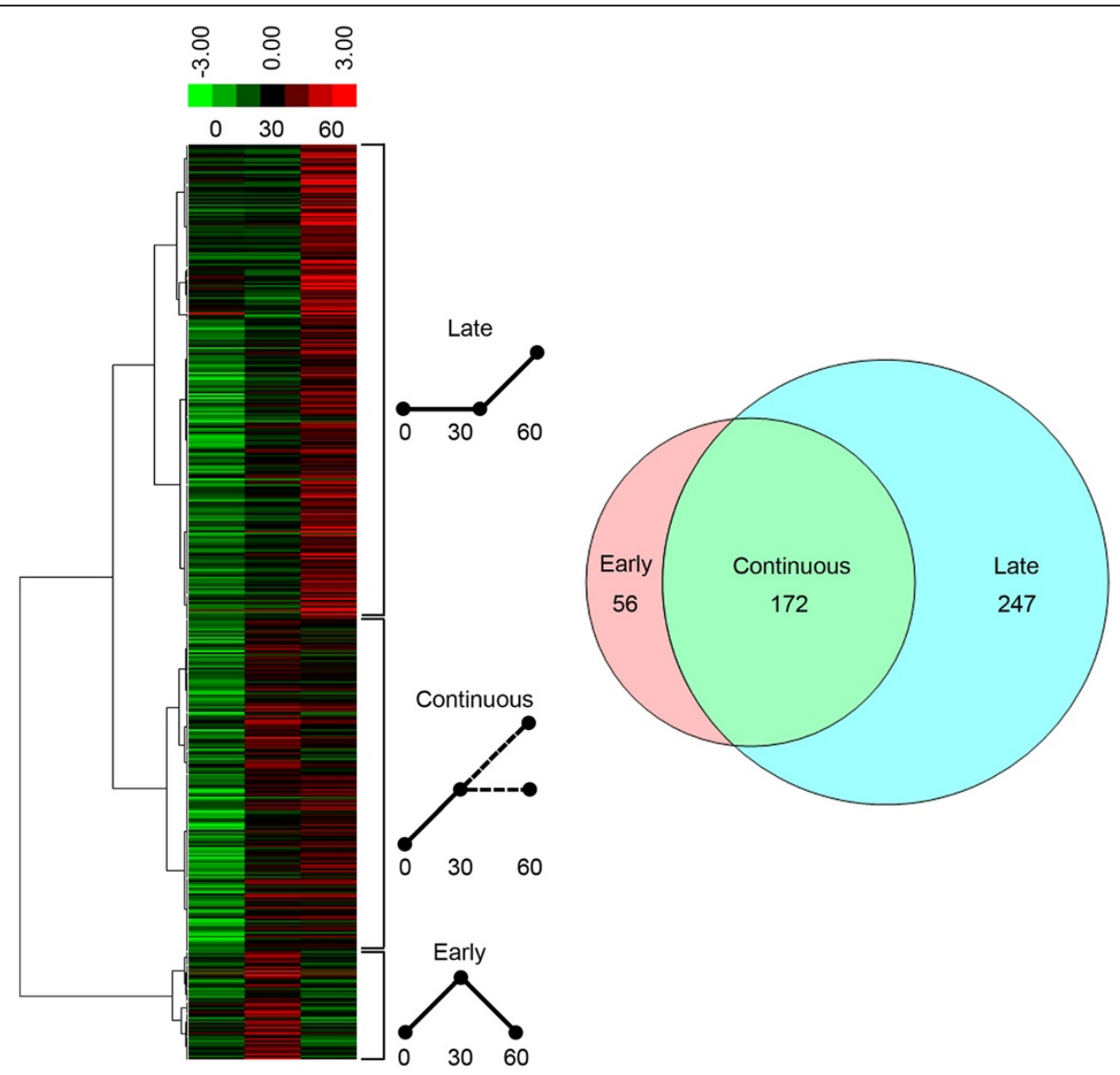

Figure 5 Translational response to thermal stress. Hierarchical clustering of mRNAs that showed temperature-dependent increases in translational efficiency fell into three major clusters (left). A schematic representation of each pattern of translational efficiency change is shown in the center: Late (increased at $60 \mathrm{~min}$ ), Continuous (increased at $30 \mathrm{~min}$ and maintained or further increased at $60 \mathrm{~min}$, and Early (transient increase at $30 \mathrm{~min}$ ). The Venn diagram illustrates the number of mRNAs in each category. 


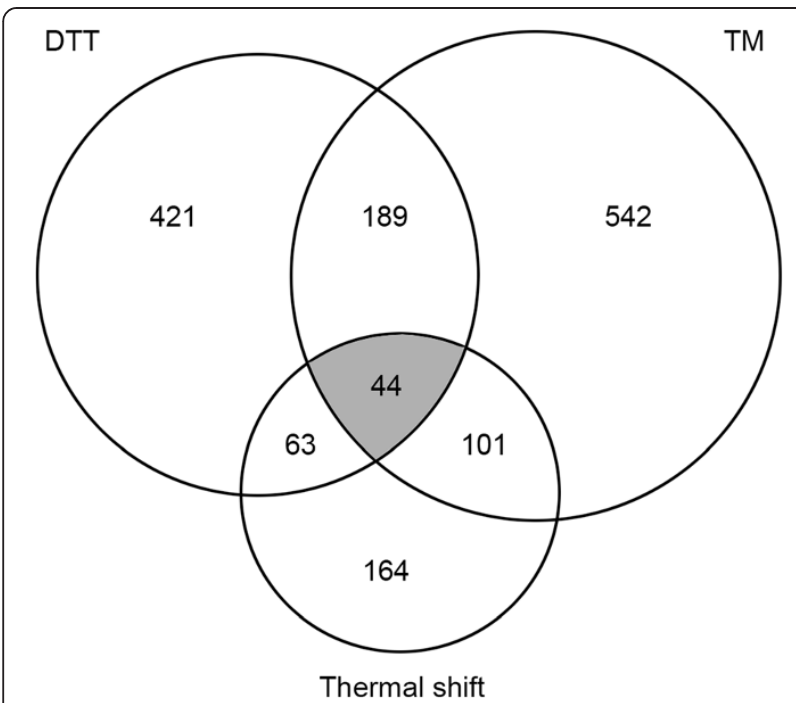

Figure 6 Summary of translationally upregulated mRNAs. The Venn diagram shows the number of transcripts with a higher translational efficiency (2-fold change) when treated with DTT or TM or when moved from $25^{\circ} \mathrm{C}$ to $37^{\circ} \mathrm{C}$ for $1 \mathrm{~h}$. The overlapping region (shaded) represents a core set of translationally up-regulated genes that respond to all three types of stress in A. fumigatus.

this study. A total of 44 mRNAs were shared between the three datasets, only one of which encoded a classical ER stress response protein involved in protein folding, TigA (Additional file 4). These findings demonstrate the remarkable breadth of functions that underpin ER homeostatic functions in this organism.

\section{The ER stress translatome contains a UPR-dependent mRNA isoform}

The regulation of mRNA translation efficiency can occur by a variety of mechanisms, one of which includes alterations in the mRNA sequence that enhance translatability [47]. To determine whether ER stress induces changes in mRNA structure, whole transcriptome shotgun sequencing (RNA-seq) was performed in the presence or absence of DTT. The RNA-seq coverage plot for the hacA mRNA served as a control for this analysis, revealing splicing of the same conventional and unconventional introns that have been validated experimentally [7] (Figure 7). A substantial amount of unconventional intron splicing was evident in the absence of DTT, consistent with our previous finding that $A$. fumigatus relies upon the UPR even during normal vegetative growth [6]. This contrasts the situation in S. cerevisiae, where there is minimal splicing of HAC1 in the absence of exogenous ER stress [27], possibly due to the decreased demands on the secretory pathway in a unicellular yeast. As expected, treatment of $A$. fumigatus with DTT was associated with an increase in reads across the length of the hacA gene (Figure 7), with the exception of the unconventional intron, demonstrating an increase in the ratio of spliced to unspliced hacA RNA under these conditions. The unconventional intron in A. fumigatus hacA is only 20 nucleotides in length, which is similar to what has been reported in the human homolog but strikingly different from the 252 nucleotide intron in the $S$. cerevisiae homolog. In $S$. cerevisiae, the unconventional intron blocks translation of the mRNA by forming a stem-loop structure with the 5'UTR [48]. The removal of the intron by Ire1-mediated splicing releases this translation block, allowing the spliced mRNA to be translated. The small size of the hacA intron in A. fumigatus makes a similar translation block mechanism unlikely, similar to what has been reported in mammals, Caenorhabditis elegans, Candida albicans, and other filamentous fungi $[12,49-52]$. In fact, the unspliced mRNA in humans is translated into a protein product that contains a hydrophobic segment that tethers the mRNA to the ER membrane, thereby facilitating splicing by Ire1 [53]. In A. fumigatus, both the unspliced and spliced hacA mRNAs can be readily identified in fraction-W by RT-PCR (data not shown), suggesting the possibility that the unspliced RNA is translated. It will be interesting to determine whether its putative encoded product is involved in a similar ER membrane tethering mechanism in A. fumigatus.

We next analyzed the RNA-seq profiles of all 233 translationally upregulated mRNAs identified in our ER stress study (Figure 2). The RNA-seq coverage plot of the mRNA encoded by AfuA_3G13490 showed a striking change in the presence of DTT (Figure 7). This mRNA encodes the A. fumigatus homolog of yeast Yvc1, a transient receptor potential (TRP) channel protein in the vacuolar membrane that is the major release mechanism for intracellular calcium stores [54]. In the absence of DTT, the number of sequence reads was comparable along the length of the $y v c 1$ mRNA (Figure 7, red tracing), with the exception of 4 predicted introns denoted by the vertical columns. However, DTT treatment induced an increase in sequence reads, but only at the 3'-end of the gene (Figure 7, blue tracing). This mRNA did not splice out introns 3 and 4, suggesting that DTT stress was inducing a novel mRNA isoform derived from the $y v c 1$ transcription unit, henceforth referred to as $y v c 1 a$. Northern blot analysis using the full-length $y v c 1$ open reading frame (orf) as a probe confirmed that ER stress induced $y v c 1 a$ expression, but osmotic stress with $\mathrm{NaCl}$ did not (Figure 8). In addition, DTT failed to induce $y v c 1 a$ in two UPR mutants, $\triangle i r e A$ and $\triangle h a c A$, indicating that its presence is both ER stress-specific and downstream of the UPR. Sequence analysis of the $y v c 1 a$ cDNA identified a single long open reading frame that would encode the C-terminal 127 amino acids of the full-length Yvc1 protein (accession \#: XP_001481630.1). Although the oligonucleotide used for microarray hybridization would not distinguish $y v c 1 a$ from $y v c 1$, RT-PCR analysis confirmed that both mRNAs 


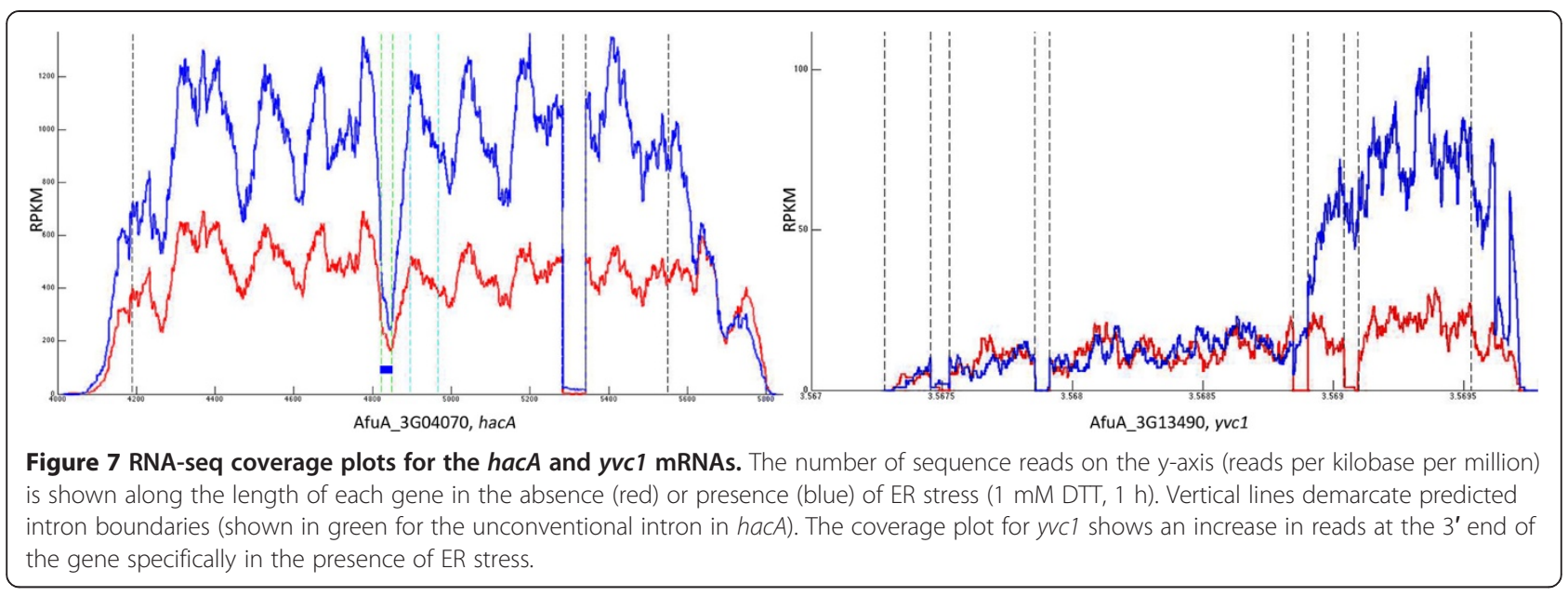

are located in fraction-W during ER stress (data not shown), suggesting that both of them contribute to the ER stress response. No alternative $Y V C 1$ isoforms could be identified in S. cerevisiae treated with either DTT or TM (data not shown), suggesting a fundamental difference between fungal genera that may reflect the increased complexity of ER stress mechanisms among filamentous fungi. Since yeast Yvc1 has a role in calcium homeostasis [54], it is appealing to speculate that the alternative isoform of this protein provides a novel regulatory mechanism to link ER stress with calcium signaling. The precise nature of the protein product encoded by this novel mRNA, its contribution to the biology of $A$. fumigatus, and the molecular

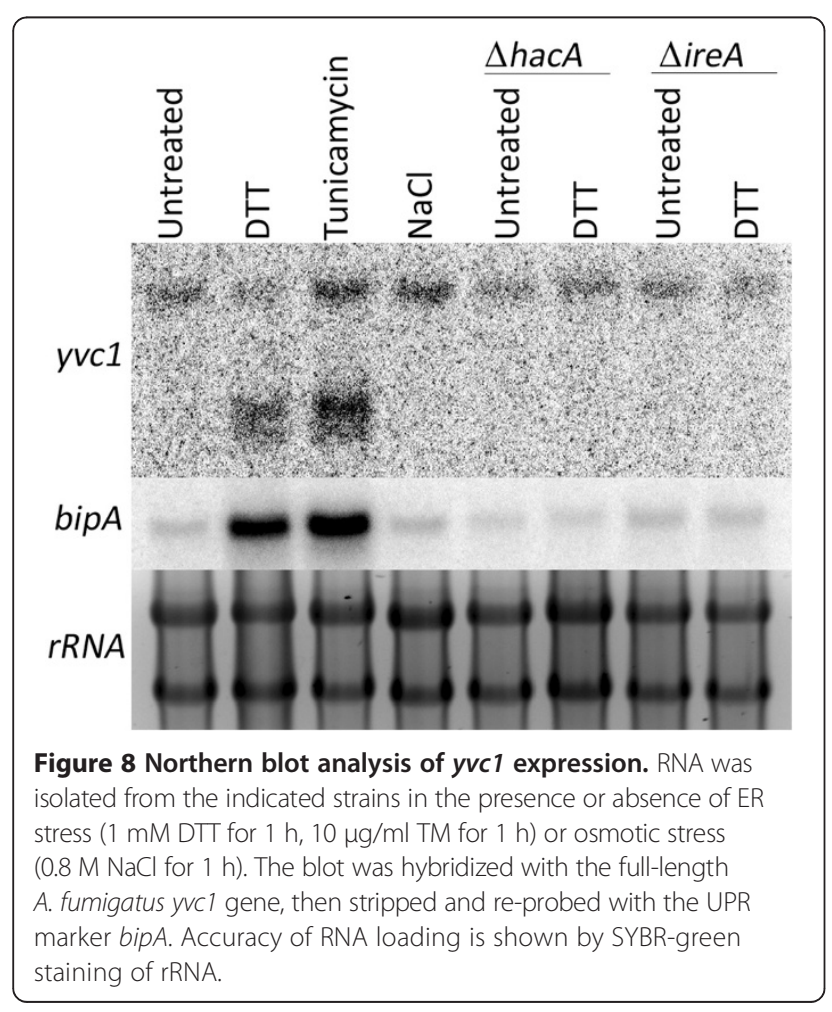

mechanisms that enhance its ribosome occupancy during ER stress are currently under active investigation.

\section{Conclusions}

In summary, this study reports the first global analysis of transcript-specific translational regulation during ER stress in the pathogenic mold A. fumigatus. The results define a core ER stress translatome and demonstrate that translational regulation is a major component of the response of A. fumigatus to environmental conditions that perturb ER homeostasis. We also provide evidence that the ER stress translatome contains a previously unidentified mRNA that is induced by ER stress in a UPR-dependent manner. Together with our previous analysis of the UPR transcriptome, these findings begin to develop a comprehensive understanding of how A. fumigatus responds to ER stress. Since ER stress is experienced by several fungal pathogens in the host environment [6-10], further understanding of these pathways, and the mechanisms used to deploy them, may provide a new perspective on fungal pathogenesis and offer novel strategies for therapeutic intervention.

\section{Methods}

\section{Strains and culture conditions}

The wt strain used in this study is AfS28 ( $\triangle a k u A$ ::ptrA) [55]. Conidia were harvested from colonies grown on OSM plates (Aspergillus minimal medium containing $10 \mathrm{mM}$ ammonium tartrate and osmotically stabilized with 1.2 M sorbitol). For analysis of the ER stress response, a $250 \mathrm{ml}$ flask containing $50 \mathrm{ml}$ of YG medium $(0.5 \%$ yeast extract, $2 \%$ glucose) was inoculated with $5 \times 10^{7}$ conidia and incubated for $16 \mathrm{~h}$ with shaking $(200 \mathrm{rpm})$ at $37^{\circ} \mathrm{C}$. ER stress was then induced by treating the cultures with $1 \mathrm{mM}$ DTT or $10 \mu \mathrm{g} / \mathrm{ml}$ TM for $1 \mathrm{~h}$. Hyperosmotic stress was induced by adding $\mathrm{NaCl}$ to a final concentration of $0.8 \mathrm{M}$ and continuing the incubation for an additional hour. For analysis of the heat-shock response, $250 \mathrm{ml}$ 
flasks containing $50 \mathrm{ml}$ of YG medium were inoculated with $5 \times 10^{7}$ conidia and incubated for $16 \mathrm{~h}$ with shaking (200 rpm) at room temperature. Thermal stress was then applied by transferring the flasks to a shaking $37^{\circ} \mathrm{C}$ incubator $(200 \mathrm{rpm})$ and harvesting the mycelium after $30 \mathrm{~min}$ and $60 \mathrm{~min}$ of incubation.

\section{Polysome fractionation and RNA extraction}

Sample preparation and polysome analysis was performed as previously described, with modifications [56]. Following the induction of ER or thermal stress in the cultures, translating polyribosomes were halted on the mRNAs by the addition of cycloheximide to $0.1 \mathrm{mg} / \mathrm{ml}$ and incubating at $37^{\circ} \mathrm{C}$ for an additional $5 \mathrm{~min}$. The culture was then chilled in an ice bath for 5 min prior to harvesting the mycelium. The hyphae were washed twice with $5 \mathrm{ml}$ of lysis buffer (10 mM Tris- $\mathrm{HCl}$ [pH 7.5], $100 \mathrm{mM} \mathrm{NaCl}$, $30 \mathrm{mM} \mathrm{MgCl}, 0.1 \mathrm{mg} / \mathrm{ml}$ cycloheximide, and $0.2 \mathrm{mg} / \mathrm{ml}$ heparin), flash frozen in liquid nitrogen and mechanically crushed. After resuspending in $0.5 \mathrm{ml}$ of lysis buffer, the lysate was cleared by two subsequent microcentrifugation steps $\left(15,000 \mathrm{x} \mathrm{g}\right.$, for $5 \mathrm{~min}$ at $\left.4^{\circ} \mathrm{C}\right)$ and the RNA content in the supernatant was quantified by absorbance at $260 \mathrm{~nm}$. Equal amounts of RNA (20-30 A 260 units) were loaded onto a 12 -ml linear sucrose gradient $(7-47 \%)$ prepared in gradient buffer $(50 \mathrm{mM}$ Tris-acetate, $50 \mathrm{mM}$ $\mathrm{NH}_{4} \mathrm{Cl}, 12 \mathrm{mM} \mathrm{MgCl}, 1 \mathrm{mM}$ DTT, and $0.2 \mathrm{mg} / \mathrm{ml}$ heparin). The gradients were centrifuged at $150,000 \times \mathrm{g}$ for $2.5 \mathrm{~h}$ at $4^{\circ} \mathrm{C}$, using a Sorvall SW $41 \mathrm{Ti}$ rotor. Gradient analysis was performed using an ISCO gradient collector with continuous monitoring at $254 \mathrm{~nm}$. Individual fractions were collected with a Foxy Jr. fraction collector and RNA was precipitated from $0.5 \mathrm{ml}$ fractions by mixing with an equal volume of $6 \mathrm{M}$ guanidine thiocyanate and 2 volumes of $100 \%$ ethanol and incubating overnight at $-20^{\circ} \mathrm{C}$. The RNA was pelleted, washed and resuspended using standard procedures. For microarray analysis, RNA from fractions containing less than 5 ribosomes/ mRNA (' $U$ ') or 5 or more ribosomes/mRNA ('W') were pooled and precipitated with $1.5 \mathrm{M} \mathrm{LiCl}$, followed by washing to remove residual heparin. For northern blot analysis of erg1 expression, the sucrose gradient was divided into seven sequential fractions representing the entire gradient, and the RNA was precipitated as indicated above. For experiments that required unfractionated RNA (unfractionated controls for the thermal shift microarray experiment, northern blot analysis of erg1 mRNA, and RNA-seq analysis of DTT-treated cultures), the mycelium was crushed in liquid nitrogen and total RNA was extracted using the TRIZOL method [57].

\section{Microarray hybridization}

The RNA labeling reactions and hybridizations were performed as described in the J. Craig Venter Institute
(JCVI) standard operating procedure http://pfgrc.jcvi. org/index.php/microarray/protocols.html) and transcriptional profiles were generated by interrogating the Af293 spotted oligonucleotide microarray containing 10, 503 spots. Each gene was present in triplicate on the array, and all hybridizations were repeated in dye swap experiments. The data for each gene were averaged from the triplicate genes on each array and the duplicate dye swap experiment (a total of six readings for each gene) and the gene expression ratios were $\log 2$-transformed. Plotting open reading frame length against fold increase in the $\mathrm{W}$ fraction showed no bias towards longer transcripts, indicating that an increase in ribosome loading on a particular transcript is not an artifact of mRNA length (data not shown).

Functional annotation of genes present within the dataset was analyzed using FungiFun [58] and enrichment of functional groups was performed using FunCat method. Hierarchical clustering was performed using Cluster 3.0 [59] and the cluster tree was visualized using JAVA Treeview [60]. All RNA samples were hybridized with a reference sample obtained from Af293 in order to allow for crosscomparison. The translational efficiency of individual mRNAs during DTT/TM treatment was defined as the ratio of the hybridization signal in fraction-W over that of fraction- $\mathrm{U}$, using a 2-fold difference between conditions as the cut-off value for a change in translational efficiency. Normalization to total mRNA abundance was not performed because the mRNAs that fit these criteria showed no increase in abundance under the same conditions [6].

The translational efficiency of individual mRNAs at $25^{\circ} \mathrm{C}$ and following a temperature shift to $37^{\circ} \mathrm{C}$ (after $30 \mathrm{~min}$ or $60 \mathrm{~min}$ ) was defined as the ratio of the hybridization signal in fraction-W over that of fraction- $\mathrm{U}$, using a 2 -fold change between conditions as the cut-off value for a change in translational efficiency. In order to enrich for mRNAs that are predominantly regulated by changes in translational efficiency (as opposed to transcript abundance), the dataset was normalized to transcript levels in unfractionated RNA. RNA abundance was determined by interrogating the microarrays with unfractionated RNA and the change in the translational efficiency of each mRNA upon thermal shift was calculated as (fraction-W/ fraction-U)/total transcript abundance.

\section{RNA sequencing}

RNA-seq was performed by the Genomics Sequencing Core (GSC) at the University of Cincinnati. Using TruSeq RNA sample preparation kit (Illumina), total RNA (RIN $\geq$ 7.0, Agilent 2100 Bioanalyzer) was converted into a library of template molecules suitable for subsequent cluster generation and sequencing by Illumina HiSeq. Poly $(\mathrm{A})_{\mathrm{n}}$ mRNA was extracted and fragmented into smaller pieces ( 140 nt). The cleaved RNA fragments were converted 
into first strand cDNA using reverse transcriptase and random primers, followed by second strand synthesis using DNA polymerase I and RNAse $\mathrm{H}$. The cDNA fragments were then subject to end-repair followed by addition of a single 'A' base and ligation of adapters. The products were indexed individually, purified and enriched by PCR to create the final cDNA library. The generated library was validated and quantified using Kapa Library Quantification kit (Kapabiosystem). Six individually indexed cDNA libraries of equal amounts were pooled for clustering in cBot system (Illumina). Libraries were clustered onto a flow cell using Illumina's TruSeq SR Cluster Kit v3, and sequenced for 50 cycles using TruSeq SBS kit on Illumina HiSeq system.

FASTQ files containing 50 bp single-end RNA-Seq reads were mapped to the Aspergillus fumigatus genome sequence (taxid:330879) by TopHat [61]. Transcript assembly and abundance estimation were performed by Cufflinks [62].

Reads corresponding to 233 genes of interest were filtered and the coverage of each nucleotide position was counted using a semi-automated method in order to ensure accuracy of analysis. Coverage plots for each of the 233 genes under two conditions were plotted using Matlab .

\section{Analysis of mRNA expression by northern blot analysis and $\mathrm{QPCR}$}

RNA samples were fractionated by formaldehyde gel electrophoresis, and visualized by SYBR green staining. The RNA was then transferred to BioBond nylon membranes (Sigma) and hybridized to a ${ }^{32} \mathrm{P}$-labeled DNA probe as previously described [7]. Probes specific for the A. fumigatus erg1, yvc1 and bipA genes were PCR amplified from genomic DNA using the following primers: erg1: 5'CGTCAGTGTTGTTGAGAC-3' and 5' - GAAGGTCGA GAGCTGCTTC-3'; yvc1: 5' - CAATGCTGTGGACGA GTACATG-3' and 5' - GTGCTCCTCTGTATCCTTC TTC-3'; bipA: 5' - GTCTGATTGGACGCAAGTTC-3' and 5' - ATCTGGGAAGACAGAGTACG-3'. Hybridization intensities were quantified by phosphorimager analysis using Image Lab software.

For qPCR analysis one $\mu \mathrm{g}$ of RNA from pooled fractions corresponding to fraction- $\mathrm{U}$ or fraction-W was reversetranscribed with M-MuLV reverse transcriptase (NEB) using oligo $(\mathrm{dT})_{18}$ and $18 \mathrm{~S}$ rRNA primers (primer 713-TGAGCCGATAGTCCCCCTAA and primer 714GACTCAACACGGGGAAACTC). The qPCR was performed using the $\mathrm{iTaq}^{\mathrm{Tn}}$ universal $\mathrm{SYBR}^{\circ}$ green supermix (Bio-Rad) according to the manufacturer's protocol. The melting curve was monitored to verify specificity of the amplification reaction. Controls reactions in the absence of reverse transcriptase were used verify the absence of DNA contamination. The 18S rRNA present within fraction- $\mathrm{U}$ or fraction- $\mathrm{W}$ was used as an endogenous control to derive a $\Delta \mathrm{Ct}$ value for each fraction. A translational efficiency ratio $(\mathrm{W} / \mathrm{U})$ was derived by subtracting $\Delta \mathrm{Ct}$ of fraction-W from that of fraction-U, representing $\Delta \Delta \mathrm{Ct}$. Change in W/U ratios upon treatment with DTT or TM was then plotted using $2-\Delta \Delta C t$ of untreated samples as the reference. Primers used for qRT-PCR are as follows: $\beta$-tubulin (AfuA_1g10910), primer 554-CACGGATCTT GGAGATC and primer 562-ACAACTTCGTCTTCGG CCAG; squalene monooxygenase erg1 (AfuA_5g07780), primer 810-AGCTGCGATCTATGCCGAATTCCT and primer 799-TCCCAGTTGGAAGTAACGGAAGCA; vacuolar protein sorting 55 superfamily vps55 (AFUA_6G04 780), primer 804-GCGCTCTCCTTTGTTCTTGCCATT and primer 805-AAGACCTCCGAGGATGGACATGAT; bZIP transcription factor jlbA/IDI-4 (AFUA_5G01650), primer 813-TTGATGTGAACGACTCTCTGCCGT and primer 814-TAGCTTCGACACCCGCATCTTCAA. The data were compared by Student's t-test and a $\mathrm{p}<0.05$ was considered significant (indicated by the asterisk, Additional file 1).

\section{Data availability}

The microarray and RNA-seq data sets reported in this article are available in the ArrayExpress database (microarray accession E-MTAB-2027, RNA-seq accession ERP004296).

\section{Additional files}

\begin{tabular}{|c|}
\hline $\begin{array}{l}\text { Additional file 1: Validation of the translationally regulated dataset } \\
\text { by qPCR. The levels of } 18 \mathrm{~S} \text { rRNA in fraction- } U \text { or fraction-W was used as an } \\
\text { endogenous control to derive a } \Delta C \mathrm{Ct} \text { value for each fraction. A translational } \\
\text { efficiency ratio (W/U) was then calculated by subtracting } \Delta C \mathrm{C} \text { of fraction-W } \\
\text { from that of fraction-U, representing } \Delta \Delta C \mathrm{Ct} \text {. The change in W/U ratios upon } \\
\text { treatment with } D T T \text { or TM was then plotted using } 2-\Delta \Delta C \mathrm{Ct} \text { of untreated } \\
\text { samples (UT) as the reference. }\end{array}$ \\
\hline $\begin{array}{l}\text { Additional file 2: List of mRNAs with decreased polysome } \\
\text { association during ER stress (treatment with DTT or TM). Values } \\
\text { represent log2 [translational state efficiency], as described in Methods. }\end{array}$ \\
\hline $\begin{array}{l}\text { Additional file 3: List of over-represented KEGG pathways in the } \\
\text { dataset of translationally regulated mRNA following a shift to } 37^{\circ} \mathrm{C} \text {. }\end{array}$ \\
\hline $\begin{array}{l}\text { Additional file 4: List of mRNAs with increased polysome } \\
\text { association during each of the three forms of ER stress: treatment } \\
\text { with DTT, TM and thermal stress. Values represent log2[translational } \\
\text { efficiency ratio], as described in Methods. "mRNAs subject to translational } \\
\text { upregulation in the thermal stress dataset at } 60 \text { min. }\end{array}$ \\
\hline
\end{tabular}

\section{Abbreviations}

ER: Endoplasmic reticulum; UPR: Unfolded protein response; RNAse: Endoribonuclease; DTT: Dithiothreitol; TM: Tunicamycin; KEGG: Kyoto Encyclopedia of Genes and Genomes; GPI: Glycosylphosphatidylinositol; TRP: Transient receptor potential; YG: Yeast extract/glucose medium.

Competing interests

The authors declare that they have no competing interests.

\section{Authors' contributions}

KK performed the polysome fractionation, RNA isolation, and drafted the manuscript. ZR and LJL performed the RNA-seq analysis. KK, LL, WCN and 
DSA performed the microarray hybridization analysis. DSA conceived of the study, participated in its design and coordination and helped to draft the manuscript. All authors read and approved the final manuscript.

\section{Acknowledgements}

Supported by National Institutes of Health grant R21A1075237 and R01Al072297 to DSA. The authors thank Jay Card for photography and illustration assistance.

\section{Author details}

${ }^{1}$ Department of Pathology \& Laboratory Medicine, University of Cincinnati College of Medicine, 231 Albert Sabin Way, Cincinnati, OH 45267-0529, USA. ${ }^{2}$ Division of Biomedical Informatics, Cincinnati Children's Hospital Research Foundation, Cincinnati, OH 45229, USA. ${ }^{3}$ The J. Craig Venter Institute, 9704 Medical Center Drive, Rockville, MD 20850, USA. ${ }^{4}$ Department of Pathology, University of Cincinnati, PO Box 670529, Cincinnati, OH 45267-0529, USA.

Received: 17 October 2013 Accepted: 17 February 2014

Published: 25 February 2014

\section{References}

1. Shoham S, Marr KA: Invasive fungal infections in solid organ transplant recipients. Future Microbiol 2012, 7(5):639-655.

2. Segal BH: Aspergillosis. N Engl J Med 2009, 360(18):1870-1884.

3. Kim A, Nicolau DP, Kuti JL: Hospital costs and outcomes among intravenous antifungal therapies for patients with invasive Aspergillosis in the United States. Mycoses 2011, 54(5):e301-312.

4. Wilson LS, Reyes CM, Stolpman M, Speckman J, Allen K, Beney J: The direct cost and incidence of systemic fungal infections. Value Health 2002, 5(1):26-34.

5. Lin SJ, Schranz J, Teutsch SM: Aspergillosis case-fatality rate: systematic review of the literature. Clin Infect Dis 2001, 32(3):358-366.

6. Feng X, Krishnan K, Richie DL, Aimanianda V, Hartl L, Grahl N, PowersFletcher MV, Zhang M, Fuller KK, Nierman WC, et al: HacA-independent functions of the ER stress sensor IreA synergize with the canonical UPR to influence virulence traits in Aspergillus fumigatus. PLOS Pathog 2011, 7(10):e1002330.

7. Richie DL, Hartl L, Aimanianda V, Winters MS, Fuller KK, Miley MD, White S, McCarthy JW, Latge JP, Feldmesser M, et al: A role for the unfolded protein response (UPR) in virulence and antifungal susceptibility in Aspergillus fumigatus. PLoS Pathog 2009, 5(1):e1000258.

8. Cheon SA, Jung KW, Chen YL, Heitman J, Bahn YS, Kang HA: Unique evolution of the UPR pathway with a novel bZIP transcription factor, Hxl1, for controlling pathogenicity of Cryptococcus neoformans. PLoS Pathog 2011, 7(8)::1002177.

9. Joubert A, Simoneau P, Campion C, Bataille-Simoneau N, lacomi-Vasilescu B, Poupard P, Francois JM, Georgeault S, Sellier E, Guillemette T: Impact of the unfolded protein response on the pathogenicity of the Neurotrophic fungus Alternaria brassicicola. Mol Microbiol 2011, 79(5):1305-1324.

10. Miyazaki T, Nakayama H, Nagayoshi Y, Kakeya H, Kohno S: Dissection of Ire1 functions reveals stress response mechanisms uniquely evolved in Candida glabrata. PLoS Pathog 2013, 9(1):e1003160.

11. Gardner BM, Pincus D, Gotthardt K, Gallagher CM, Walter P: Endoplasmic reticulum stress sensing in the unfolded protein response. Cold Spring Harbor Perspect Biol 2013, 5(3):a013169.

12. Wimalasena TT, Enjalbert B, Guillemette T, Plumridge A, Budge S, Yin Z, Brown AJ, Archer DB: Impact of the unfolded protein response upon genome-wide expression patterns, and the role of $\mathrm{Hac} 1$ in the polarized growth, of Candida albicans. Fungal Genet Biol 2008, 45(9):1235-1247.

13. Hartmann T, Sasse C, Schedler A, Hasenberg M, Gunzer M, Krappmann S: Shaping the fungal adaptome-stress responses of Aspergillus fumigatus. Int J Med Microbiol 2011, 301(5):408-416.

14. Kohno K: Stress-sensing mechanisms in the unfolded protein response: similarities and differences between yeast and mammals. J Biochem 2010, 147(1):27-33.

15. Kimata Y, Oikawa D, Shimizu Y, Ishiwata-Kimata Y, Kohno K: A role for BiP as an adjustor for the endoplasmic reticulum stress-sensing protein Ire1. J Cell Biol 2004, 167(3):445-456.

16. Gardner BM, Walter P: Unfolded proteins are Ire1-activating ligands that directly induce the unfolded protein response. Science 2011, 333(6051):1891-1894.
17. Kimata $Y$, Ishiwata-Kimata $Y$, Ito T, Hirata A, Suzuki T, Oikawa D, Takeuchi M, Kohno K: Two regulatory steps of ER-stress sensor Ire1 involving its cluster formation and interaction with unfolded proteins. J Cell Biol 2007, 179(1):75-86.

18. Credle JJ, Finer-Moore JS, Papa FR, Stroud RM, Walter P: On the mechanism of sensing unfolded protein in the endoplasmic reticulum. Proc Natl Acad Sci USA 2005, 102(52):18773-18784.

19. Korennykh AV, Egea PF, Korostelev AA, Finer-Moore J, Zhang C, Shokat KM, Stroud RM, Walter P: The unfolded protein response signals through high-order assembly of Ire1. Nature 2009, 457(7230):687-693.

20. Shamu CE, Walter P: Oligomerization and phosphorylation of the Ire $1 p$ kinase during intracellular signaling from the endoplasmic reticulum to the nucleus. EMBO J 1996, 15(12):3028-3039.

21. Gygi SP, Rochon $Y$, Franza BR, Aebersold R: Correlation between protein and mRNA abundance in yeast. Mol Cell Biol 1999, 19(3):1720-1730.

22. Washburn MP, Koller A, Oshiro G, Ulaszek RR, Plouffe D, Deciu C, Winzeler E, Yates JR 3rd: Protein pathway and complex clustering of correlated mRNA and protein expression analyses in Saccharomyces cerevisiae. Proc Natl Acad Sci USA 2003, 100(6):3107-3112.

23. Greenbaum D, Colangelo C, Williams K, Gerstein M: Comparing protein abundance and mRNA expression levels on a genomic scale. Genome Biol 2003, 4(9):117.

24. Gebauer F, Hentze MW: Molecular mechanisms of translational control. Nat Rev Mol Cell Biol 2004, 5(10):827-835.

25. Halbeisen RE, Gerber AP: Stress-dependent coordination of transcriptome and translatome in yeast. PLOS Biol 2009, 7(5):e1000105.

26. Beilharz TH, Preiss T: Translational profiling: the genome-wide measure of the nascent proteome. Brief Funct Genom Proteom 2004, 3(2):103-111.

27. Payne T, Hanfrey C, Bishop AL, Michael AJ, Avery SV, Archer DB: Transcriptspecific translational regulation in the unfolded protein response of Saccharomyces cerevisiae. FEBS Lett 2008, 582(4):503-509.

28. Guillemette T, van Peij NN, Goosen T, Lanthaler K, Robson GD, van den Hondel CA, Stam H, Archer DB: Genomic analysis of the secretion stress response in the enzyme-producing cell factory Aspergillus niger. BMC Genomics 2007, 8:158.

29. Back SH, Schroder M, Lee K, Zhang K, Kaufman RJ: ER stress signaling by regulated splicing: IRE1/HAC1/XBP1. Methods 2005, 35(4):395-416.

30. Harding HP, Zhang Y, Ron D: Protein translation and folding are coupled by an endoplasmic-reticulum-resident kinase. Nature 1999, 397(6716):271-274.

31. Korennykh A, Walter P: Structural basis of the unfolded protein response. Ann Rev Cell Dev Biol 2012, 28:251-277.

32. Warner JR, Mclntosh KB: How common are extraribosomal functions of ribosomal proteins? Mol Cell 2009, 34(1):3-11.

33. Gastebois A, Clavaud C, Aimanianda V, Latge JP: Aspergillus fumigatus: cell wall polysaccharides, their biosynthesis and organization. Future Microbiol 2009, 4(5):583-595.

34. Mo C, Bard M: Erg28p is a key protein in the yeast sterol biosynthetic enzyme complex. J Lipid Res 2005, 46(9):1991-1998.

35. Lewis RE, Viale P, Kontoyiannis DP: The potential impact of antifungal drug resistance mechanisms on the host immune response to Candida. Virulence 2012, 3(4):368-376.

36. Hartland RP, Fontaine T, Debeaupuis JP, Simenel C, Delepierre M, Latge JP. A novel beta-(1-3)-glucanosyltransferase from the cell wall of Aspergillus fumigatus. J Biol Chem 1996, 271(43):26843-26849.

37. Mouyna I, Morelle W, Vai M, Monod M, Lechenne B, Fontaine T, Beauvais A Sarfati J, Prevost MC, Henry C, et al: Deletion of GEL2 encoding for a beta (1-3)glucanosyltransferase affects morphogenesis and virulence in Aspergillus fumigatus. Mol Microbiol 2005, 56(6):1675-1688.

38. Li H, Zhou H, Luo Y, Ouyang H, Hu H, Jin C: Glycosylphosphatidylinositol (GPI) anchor is required in Aspergillus fumigatus for morphogenesis and virulence. Mol Microbiol 2007, 64(4):1014-1027.

39. Gastebois A, Fontaine T, Latge JP, Mouyna I: beta(1-3) Glucanosyltransferase Gel4p is essential for Aspergillus fumigatus. Eukaryot Cell 2010, 9(8):1294-1298.

40. Hata K, Horii T, Miyazaki M, Watanabe NA, Okubo M, Sonoda J, Nakamoto K, Tanaka K, Shirotori S, Murai N, et al: Efficacy of oral E1210, a new broadspectrum antifungal with a novel mechanism of action, in murine models of candidiasis, Aspergillosis, and fusariosis. Antimicrob Agents Chemother 2011, 55(10):4543-4551. 
41. Miyazaki M, Horii T, Hata K, Watanabe NA, Nakamoto K, Tanaka K, Shirotori S, Murai N, Inoue S, Matsukura M, et al: In vitro activity of E1210, a novel antifungal, against clinically important yeasts and molds. Antimicrob Agents Chemother 2011, 55(10):4652-4658.

42. McLellan CA, Whitesell L, King OD, Lancaster AK, Mazitschek R, Lindquist S: Inhibiting GPI anchor biosynthesis in fungi stresses the endoplasmic reticulum and enhances immunogenicity. ACS Chem Biol 2012, 7(9):1520-1528.

43. Bhabhra R, Askew DS: Thermotolerance and virulence of Aspergillus fumigatus: role of the fungal nucleolus. Med Mycol 2005 43(Suppl 1):S87-S93.

44. Matsumoto R, Akama K, Rakwal R, Iwahashi $H$ : The stress response against denatured proteins in the deletion of cytosolic chaperones SSA1/2 is different from heat-shock response in Saccharomyces cerevisiae. BMC Genomics 2005, 6:141.

45. Do JH, Yamaguchi R, Miyano S: Exploring temporal transcription regulation structure of Aspergillus fumigatus in heat shock by state space model. BMC Genomics 2009, 10:306.

46. Nierman WC, Pain A, Anderson MJ, Wortman JR, Kim HS, Arroyo J, Berriman M, Abe K, Archer DB, Bermejo C, et al: Genomic sequence of the pathogenic and allergenic filamentous fungus Aspergillus fumigatus. Nature 2005, 438(7071):1151-1156.

47. Mulder HJ, Nikolaev I: HacA-dependent transcriptional switch releases hacA mRNA from a translational block upon endoplasmic reticulum stress. Eukaryot Cell 2009, 8(4):665-675.

48. Ruegsegger $U$, Leber $\mathrm{H}$, Walter P: Block of HAC1 mRNA translation by long-range base pairing is released by cytoplasmic splicing upon induction of the unfolded protein response. Cell 2001, 107(1):103-114.

49. Hooks KB, Griffiths-Jones S: Conserved RNA structures in the noncanonical Hac1/Xbp1 intron. RNA Biol 2011, 8(4):552-556.

50. Calfon M, Zeng H, Urano F, Till JH, Hubbard SR, Harding HP, Clark SG, Ron D: IRE1 couples endoplasmic reticulum load to secretory capacity by processing the XBP-1 mRNA. Nature 2002, 415(6867):92-96.

51. Mulder HJ, Saloheimo M, Penttila M, Madrid SM: The transcription factor HACA mediates the unfolded protein response in Aspergillus niger, and up-regulates its own transcription. Mol Genet Genomics 2004, 271(2):130-140.

52. Saloheimo M, Valkonen $M$, Penttila M: Activation mechanisms of the HAC1-mediated unfolded protein response in filamentous fungi. Mol Microbiol 2003, 47(4):1149-1161.

53. Yanagitani K, Imagawa Y, Iwawaki T, Hosoda A, Saito M, Kimata Y, Kohno K. Cotranslational targeting of XBP1 protein to the membrane promotes cytoplasmic splicing of its own mRNA. Mol Cell 2009, 34(2):191-200.

54. Denis $\mathrm{V}, \mathrm{Cyert} \mathrm{MS}$ : Internal $\mathrm{Ca}(2+)$ release in yeast is triggered by hypertonic shock and mediated by a TRP channel homologue. J Cell Biol 2002, 156(1):29-34

55. Krappmann S, Sasse C, Braus GH: Gene targeting in Aspergillus fumigatus by homologous recombination is facilitated in a nonhomologous endjoining-deficient genetic background. Eukaryot Cell 2006, 5(1):212-215.

56. Bhabhra R, Richie DL, Kim HS, Nierman WC, Fortwendel J, Aris JP, Rhodes JC, Askew DS: Impaired ribosome biogenesis disrupts the integration between morphogenesis and nuclear duplication during the germination of Aspergillus fumigatus. Eukaryot Cell 2008, 7(4):575-583.

57. Chomczynski P, Sacchi N: Single-step method of RNA isolation by acid guanidinium thiocyanate-phenol-chloroform extraction. Anal Biochem 1987, 162(1):156-159.

58. Priebe S, Linde J, Albrecht D, Guthke R, Brakhage AA: FungiFun: a web-based application for functional categorization of fungal genes and proteins. Fungal Genet Biol 2011, 48(4):353-358.

59. Eisen MB, Spellman PT, Brown PO, Botstein D: Cluster analysis and display of genome-wide expression patterns. Proc Natl Acad Sci USA 1998, 95(25):14863-14868
60. Saldanha AJ: Java Treeview-extensible visualization of microarray data. Bioinformatics 2004, 20(17):3246-3248.

61. Trapnell C, Pachter L, Salzberg SL: TopHat: discovering splice junctions with RNA-Seq. Bioinformatics 2009, 25(9):1105-1111.

62. Trapnell C, Hendrickson DG, Sauvageau M, Goff L, Rinn JL, Pachter L: Differential analysis of gene regulation at transcript resolution with RNA-seq. Nat Biotechnol 2013, 31(1):46-53.

doi:10.1186/1471-2164-15-159

Cite this article as: Krishnan et al:: Polysome profiling reveals broad translatome remodeling during endoplasmic reticulum (ER) stress in the pathogenic fungus Aspergillus fumigatus. BMC Genomics 2014 15:159.

\section{Submit your next manuscript to BioMed Central and take full advantage of:}

- Convenient online submission

- Thorough peer review

- No space constraints or color figure charges

- Immediate publication on acceptance

- Inclusion in PubMed, CAS, Scopus and Google Scholar

- Research which is freely available for redistribution 